\title{
Editorial
}

\section{Epidemiology and Infection - going electronic after 100 years}

Epidemiology and Infection became 100 years old in 2001. Its powers and influence however do not appear to have diminished, and, as the Senior Editor appointed in its 101st year, I am greatly honoured to be so closely associated with it. Just over 100 years after it was founded, Epidemiology and Infection is 'going electronic'. To mark both occasions we have put together a small selection of some of the most important or thoughtprovoking papers published in our first century, and have invited eminent epidemiologists and microbiologists to assess and comment on them critically in the light of modern knowledge. Naturally, to mark our coming of age in terms of modern methods of communication also, all the papers chosen for our centenary edition will be available - free - online. I am most grateful to my predecessor, Professor Bo Drasar, for putting together this unique tribute to Epidemiology and Infection, its Editors, its Editorial Board, and, not least the authors of our papers. Enjoy and marvel at our predecessors' wisdom, perspicacity and scientific rigour.

The papers, each with an expert commentary, are now available at:

http://journals.cambridge.org/jid_HYG

We have been processing many papers electronically since July 2004 and have ironed out most of the teething problems. From now, we will only accept electronic submission of manuscripts to:

http://mc.manuscriptcentral.com/cup/hyg

Authors who are unable to access this URL should contact me in the first instance.

Thank you to all our readers, authors and editors, as well as the backup staff at CUP, for making Epidemiology and Infection what it is.

NORMAN NOAH

Senior/Managing Editor 